\title{
O FUNCIONAMENTO DA ATENÇÃO NO TRABALHO DO CARTÓGRAFO
}

\author{
Virgínia Kastrup \\ Universidade Federal do Rio de Janeiro, Rio de Janeiro, Brasil
}

RESUMO: A cartografia é um método proposto por G. Deleuze e F. Guattari e que vem sendo utilizado em pesquisas de campo voltadas para o estudo da subjetividade. Adotando uma perspectiva construtivista, o artigo aborda o problema do funcionamento da atenção na etapa inicial do trabalho do cartógrafo. Baseia-se nos conceitos de atenção flutuante de S. Freud, de reconhecimento atento de H. Bergson e nas contribuições da vertente fenomenológica das ciências cognitivas contemporâneas. A atenção cartográfica é definida como concentrada e aberta, caracterizando-se por quatro variedades: o rastreio, o toque, o pouso e o reconhecimento atento.

PALAVRAS-CHAVE: Cartografia; atenção; produção de subjetividade; pesquisa de campo.

\section{THE FUNCTIONING OF ATTENTION IN THE WORK OF THE CARTOGRAPHER}

ABSTRACT: Cartography is a method proposed by G. Deleuze and F. Guattari which has been used in field researches in the context of subjectivity studies. Embracing a constructivist perspective, this article approaches the issue of the functioning of attention in the initial stage of cartographer's task. It is based on the concepts of free floating attention by S. Freud, attentive recognition by $\mathrm{H}$. Bergson and on contributions from some phenomenological works of contemporary cognitive sciences. Cartographic attention is defined as being concentrated and opened, and it is characterized by four varieties: tracing, touch, landing and attentive recognition.

KEYWORDS: cartography; attention; production of subjectivity; field research.

\section{O Funcionamento da Atenção no Trabalho do Cartógrafo}

A cartografia é um método formulado por G. Deleuze e F. Guattari (1995) que visa acompanhar um processo, e não representar um objeto. Em linhas gerais, trata-se sempre de investigar um processo de produção. De saída, a idéia de desenvolver o método cartográfico para utilização em pesquisas de campo no estudo da subjetividade se afasta do objetivo de definir um conjunto de regras abstratas para serem aplicadas. Não se busca estabelecer um caminho linear para atingir um fim. A cartografia é sempre um método ad hoc. Todavia, sua construção caso a caso não impede que se procure estabelecer algumas pistas que têm em vista descrever, discutire, sobretudo, coletivizar a experiência do cartógrafo.

A pista que tomamos aqui diz respeito ao funcionamento da atenção durante o trabalho de campo. Não se trata de buscar uma teoria geral da atenção. A idéia é que, na base da construção de conhecimento através de um método dessa natureza, há um tipo de funcionamento da atenção que foi em parte descrito por S. Freud (1912/1969) com o conceito de atenção flutuante e por H. Bergson (1897/ 1990a) com o conceito de reconhecimento atento. Através do recurso a esses conceitos, bem como a referências extraídas do campo das ciências cognitivas contemporâneas, o objetivo é analisar a etapa inicial de uma pesquisa, tradicionalmente denominada "coleta de dados". Ocorre que, do ponto de vista dos recentes estudos acerca da cognição numa perspectiva construtivista, não há coleta de dados, mas, desde o início, uma produção dos dados da pesquisa. A formulação paradoxal de uma "produção dos dados" visa ressaltar que há uma real produção, mas do que, em alguma medida, já estava lá de modo virtual. ${ }^{1}$

Há dois pontos a serem examinados. O primeiro diz respeito à própria função da atenção, que não é de simples seleção de informações. Seu funcionamento não se identifica a atos de focalização para preparar a representação das formas de objetos, mas se faz através da detecção de signos e forças circulantes, ou seja, de pontas do processo em curso. A detecção e apreensão de material, em princípio desconexo e fragmentado, de cenas e discursos, requer uma concentração sem focalização, indicada por Gilles Deleuze (2006) no seu Abécédaire através da idéia de uma atenção à espreita, cujo funcionamento vamos procurar elucidar. O segundo ponto é que a atenção, enquanto processo complexo, pode assumir diferentes funcionamentos: seletivo ou flutuante, focado ou desfocado, concentrado ou disperso, voluntário ou involuntário, em várias combinações como seleção voluntária, flutuação involuntária, concentração desfocada, focalização dispersa, etc. Embora as variedades atencionais coexistam de direito, elas ganham organizações e proporções distintas na configuração de diferentes políticas cognitivas (Kastrup, 2005).

Chamamos de política cognitiva um tipo de atitude ou de relação encarnada, no sentido em que não é consciente, que se estabelece com o conhecimento, com o mundo e consigo mesmo. Tomar o mundo como fornecendo infor- 
mações prontas para serem apreendidas é uma política cognitiva realista; tomá-lo como uma invenção, como engendrado conjuntamente com o agente do conhecimento, é um outro tipo de política, que denominamos construtivista. Neste sentido, realismo e construtivismo não são apenas posições epistemológicas abstratas, mas constituem atitudes investigativas diversas, reveladas, conforme veremos, em diferentes atitudes atencionais. Trata-se aqui de ressaltar que a atenção cartográfica - ao mesmo tempo flutuante, concentrada e aberta - é habitualmente inibida pela preponderância da atenção seletiva. O problema do aprendizado da atenção do cartógrafo é também um caso de criação do que já estava lá, tal como aparece na noção de aprendizado por cultivo, formulada por Depraz, Varela e Vermersch (2003).

Nos estudos sobre atenção realizados por W. James (1890/1945), que são até hoje referência nesta área de investigação, a seleção é considerada sua função por excelência. A seleção operada pela atenção é movida pelo interesse e concorre para a ação eficaz. Este modo de compreender a atenção, como possuindo uma função seletiva orientada pelo interesse e aplicada na ação, foi assimilado pela grande maioria das abordagens psicológicas, incidindo ainda hoje sobre os recentes estudos sobre o TDA - transtorno de déficit de atenção. Na atualidade, o exercício da força da vontade é evocado para o tratamento de tais quadros cognitivos que, no contexto de certas técnicas terapêuticas e aliada a medicamentos, configuram o que vem sendo chamado de biologia moral da atenção (Caliman, 2006; Lima, 2004). Todavia, a questão da atenção do cartógrafo coloca um outro problema, que diz respeito a um funcionamento não recoberto pela função seletiva. O próprio James reconheceu a flutuação da consciência e da atenção ao propor o conceito de fluxo do pensamento. James comparou o fluxo do pensamento ao vôo de um pássaro que desenha o céu com seus movimentos contínuos, pousando de tempos em tempos em certo lugar. Vôos e pousos diferem quanto à velocidade da mudança que trazem consigo (James, 1890/1945). O pouso não deve ser entendido como uma parada do movimento, mas como uma parada no movimento. Vôos e pousos conferem um ritmo ao pensamento e a atenção desempenha aí um papel essencial.

A entrada do aprendiz de cartógrafo no campo da pesquisa coloca imediatamente a questão de onde pousar sua atenção. Em geral ele se pergunta como selecionar o elemento ao qual prestar atenção, dentre aqueles múltiplos e variados que lhe atingem os sentidos e o pensamento. A pergunta, que diz respeito ao momento que precede a seleção, seria melhor formulada se evidenciasse o problema da própria configuração do território de observação, já que, conforme apontou M. Merleau-Ponty (1945/1999) a atenção não seleciona elementos num campo perceptivo dado, mas configura o próprio campo perceptivo. Uma outra ques- tão diz respeito a como prossegue o funcionamento atencional após o ato seletivo. As duas perguntas - que incidem sobre o antes e depois da seleção - indicam a complexidade e a densidade da chamada "coleta de dados", sublinhando a dimensão temporal da atenção do cartógrafo, a produção dos dados da pesquisa e o alcance de uma pesquisa construtivista.

Dentre as contribuições teóricas sobre variedades atencionais envolvidas no estudo da subjetividade, destaca-se a de S. Freud sobre a atenção flutuante, apresentada no conjunto de seus "estudos sobre técnica". No texto "Recomendações aos médicos que exercem a Psicanálise" Freud (1912/1969) aponta que a mais importante recomendação consiste em não dirigir a atenção para algo específico e em manter a atenção "uniformemente suspensa". Freud argumenta que o grande perigo da escuta clínica é a seleção do material trazido pelo paciente, operada com base em expectativas e inclinações do analista, tanto de natureza pessoal quanto teórica. Através da seleção, fixa-se um ponto com clareza particular e negligencia-se outros. A indesejável seleção envolve uma atenção consciente e deliberadamente concentrada. Mas Freud observa com precisão que "ao efetuar a seleção e seguir suas expectativas, estará arriscado a nunca descobrir nada além do que já sabe; e, se seguir as inclinações, certamente falsificará o que possa perceber" (Freud, 1912/1969, p. 150). Para Freud a atenção consciente, voluntária e concentrada, é o grande obstáculo à descoberta. Por outro lado, recomenda a utilização de uma atenção onde a seleção se encontra inicialmente suspensa, cuja definição é "prestar igual atenção a tudo". Esta atenção aberta, sem focalização específica, permite a captação não apenas dos elementos que formam um texto coerente e à disposição da consciência do analista, mas também do material "desconexo e em desordem caótica”.

Em seu sentido mais conhecido, a atenção flutuante é a regra técnica que, do lado do analista, corresponde à regra de associação livre da parte do analisando, permitindo a comunicação de inconsciente a inconsciente (Laplanche \& Pontalis, 1976). O uso da atenção flutuante significa que, durante a sessão, a atenção do analista fica aparentemente adormecida, até que subitamente emerge no discurso do analisando a fala inusitada do inconsciente. Em seu caráter desconexo ou fragmentado, ela desperta a atenção do analista. Mesmo que não seja capaz de compreendê-la, o analista lança tais fragmentos para sua própria memória inconsciente até que, mais à frente, eles possam vir a compor com outros e ganhar algum sentido. Falando de um inconsciente receptor, a ênfase do texto freudiano recai na atenção auditiva.

Fazendo um balanço acerca da contribuição do conceito de atenção flutuante para a discussão da atenção do cartógrafo, destaca-se a proximidade quanto à ênfase na suspensão de inclinações e expectativas do eu, que opera- 
riam uma seleção prévia, levando a um predomínio da recognição e conseqüente obturação dos elementos de surpresa presentes no processo observado. Além disto, a atenção seletiva cede lugar a uma atenção flutuante, que trabalha com fragmentos desconexos. Por outro lado, identifica-se um limite da formulação freudiana, que é voltada unicamente para a atenção auditiva. A utilização pelo cartógrafo de outras modalidades sensoriais além da audição, como é o caso da visão, exigirá explorar um desdobramento da contribuição freudiana. Outro limite diz respeito ao aprendizado da atenção flutuante, que não recebe formulação específica por parte de Freud (1912/1969) e que se reveste de especial importância para o avanço do método cartográfico.

O estudo da atenção desenvolvido no campo das ciências cognitivas contemporâneas, mais especificamente nos estudos da consciência, também contribui para o entendimento da atenção do cartógrafo. Seguindo uma abordagem fenomenológica, Pierre Vermersch (2002a, 2002b) destaca o caráter de mobilidade da atenção, a qual é definida como o fundo de flutuação da cognição. É no estudo da atenção que encontramos a possibilidade de pensar a modulação da intencionalidade. Segundo Vermersch a atenção opera mutações que modificam a estrutura intencional da consciência. O conceito de intencionalidade está na base do entendimento da cognição como relação sujeitoobjeto, mas o estudo da atenção revela uma nova faceta da consciência, não como intencionalidade, mas como domínio de mutações, inclusive da própria intencionalidade. O interessante nesta formulação é situar a flutuação como uma característica da atenção em geral, e não, como Freud (1912/1969), como um tipo específico de atenção - a flutuante. Pelo caminho das ciências cognitivas, a atenção, como flutuação de base da cognição, pode explicar as duas modalidades anteriormente citadas - a seletiva e a flutuante. A partir de sua plasticidade e de sua capacidade de transformação através do exercício, é possível abordar também o problema do aprendizado da atenção (Kastrup, 2004).

O conceito de suspensão foi formulado por E. Husserl (1998) no contexto do método da redução fenomenológica, que significa a colocação entre parênteses dos juízos sobre o mundo. A suspensão constitui uma atitude de abandono, ainda que temporário, da atitude recognitiva, dita natural pela fenomenologia. Trata-se de uma suspensão da política cognitiva realista, onde o conhecimento se organiza a partir da relação sujeito-objeto.

Depraz, Varela e Vermersch (2003) desenvolvem o que denominam de pragmática fenomenológica. Sublinham que Husserl formulou teoricamente o método da redução, sem, contudo, ter se colocado o problema de sua implementação concreta. Os autores argumentam que é preciso desenvolver um verdadeiro método de pesquisa da expe- riência e para isto descrevem e discutem algumas práticas como a meditação budista, a entrevista de explicitação, a visão estereoscópica e a sessão de psicanálise. Comentando a última, observam que a suspensão é um gesto cognitivo que refreia o fluxo do pensamento do analista, para que este possa seguir o discurso do paciente. Realizada no início da sessão, a suspensão não se mantém até o final. Durante a sessão, reflexões ou emoções do analista emergem, atravessando o campo cognitivo e devem ser reiteradamente colocadas de lado durante o processo de escuta. Outro elemento que interrompe a suspensão é a polarização dos pensamentos do analista por alguma formulação teórica, que é evocada pelo material trazido pelo analisando. Ressalta-se então um movimento de vaivém, articulando os sucessivos gestos de suspensão e as interrupções subseqüentes. Apesar de tais dificuldades na prática concreta, a atenção flutuante fica colocada como um horizonte técnico. Outro ponto destacado é que a escuta clínica é situada, e isto num duplo contexto: o micro-contexto da sessão e o macro-contexto do processo analítico como um todo. No caso da pesquisa cartográfica, pode-se situar o macro-contexto como a dinâmica de transformação do problema geral da pesquisa e os micro-contextos como a auto-definição de micro-problemas ao longo das consecutivas visitas ao campo. Esses dois contextos funcionam de acordo com uma lógica recursiva, engendrando-se de modo recíproco.

Depraz, Varela e Vermersch (2003) apontam que o gesto de suspensão desdobra-se em dois destinos da atenção. O primeiro indica uma mudança da direção da atenção. Habitualmente voltada para o exterior, ela se volta para o interior. O segundo destino implica uma mudança da qualidade ou da natureza da atenção, que deixa de buscar informações para acolher o que lhe acomete. A atenção não busca algo definido, mas torna-se aberta ao encontro. Trata-se de um gesto de deixar vir (letting go). Tanto a atenção a si quanto o gesto atencional de abertura e acolhimento ocorrem a partir da suspensão. Sendo assim, a suspensão, a redireção e o deixar vir não constituem três momentos sucessivos, mas se encadeiam, se conservando e se entrelaçando.

No caso da cartografia, a mera presença no campo da pesquisa expõe o cartógrafo a inúmeros elementos salientes, que parecem convocar a atenção. Muitos deles não passam, entretanto, de meros elementos de dispersão, no sentido em que produzem um sucessivo deslocamento do foco atencional. Portanto, há que haver cuidado, pois, como afirmou Freud (1912/1969), a suspensão deve garantir que, no princípio, tudo seja digno de atenção. Mas para Freud a atenção flutuante segue com o ajuste fino da sintonia inconsciente. São as manifestações do inconsciente que despertam a atenção aberta do analista, suscitando o gesto de prestar atenção. A abertura da atenção do cartó- 
grafo também não significa que ele deva prestar atenção a tudo o que lhe acomete. A chamada redireção é, neste sentido, uma resistência aos dispersores.

Numa linguagem fenomenológica, a suspensão é o ato de desmontagem da atitude natural, que é o regime cognitivo organizado no par sujeito-objeto e que configura a política cognitiva realista. É importante sublinhar que, quando sob suspensão, a atenção que se volta para o interior acessa dados subjetivos, como interesses prévios e saberes acumulados, ela deve descartá-los e entrar em sintonia com o problema que move a pesquisa. A atenção a si é, neste sentido, concentração sem focalização, abertura, configurando uma atitude que prepara para o acolhimento do inesperado. A atenção se desdobra na qualidade de encontro, de acolhimento. As experiências vão então ocorrendo, muitas vezes fragmentadas e sem sentido imediato. Pontas de presente, movimentos emergentes, signos que indicam que algo acontece, que há uma processualidade em curso. Algumas concorrem para modular o próprio problema, tornando-o mais concreto e bem colocado. Assim, surge um encaminhamento de solução ou uma resposta ao problema; outras experiências se desdobram em micro-problemas que exigirão tratamento em separado.

Signos são acolhidos numa atitude atencional de ativa receptividade. São especialmente interessantes quando põem problema e forçam a pensar. Neste caso, constituindo o que F. Varela (1995) chamou de breakdown, eles exigem que a atenção se detenha, produzindo uma desaceleração de seu movimento. A atenção tateia, explora cuidadosamente o que lhe afeta sem produzir compreensão ou ação imediata. Tais explorações mobilizam a memória e a imaginação, o passado e o futuro numa mistura difícil de discernir. Todos esses aspectos caracterizam o funcionamento da atenção do cartógrafo durante a produção dos dados numa pesquisa de campo. Um ponto não abordado por Depraz, Varela e Vermersch (2003), e que também não havia sido por Freud (1912/1969), diz respeito ao funcionamento da atenção após este momento de acolhimento do elemento problemático. Conforme veremos, é no trabalho operado pela atenção que podemos identificar mais incisivamente a produção de dados de uma pesquisa e a dimensão construtivista do conhecimento.

Quatro variedades da atenção do Cartógrafo: o Rastreio, o Toque, o Pouso e o

\section{Reconhecimento Atento}

Tomando como ponto de partida a idéia de uma concentração sem focalização, parece ser possível definir quatro variedades do funcionamento atencional que fazem parte do trabalho do cartógrafo. São eles o rastreio, o toque, o pouso e o reconhecimento atento.

O rastreio é um gesto de varredura do campo. Pode-se dizer que a atenção que rastreia visa uma espécie de meta ou alvo móvel. Neste sentido, praticar a cartografia en- volve uma habilidade para lidar com metas em variação contínua. Em realidade, entra-se em campo sem conhecer o alvo a ser perseguido; ele surgirá de modo mais ou menos imprevisível, sem que saibamos bem de onde. Para o cartógrafo o importante é a localização de pistas, de signos de processualidade. Rastrear é também acompanhar mudanças de posição, de velocidade, de aceleração, de ritmo. O rastreio não se identifica a uma busca de informação. A atenção do cartógrafo é, em princípio, aberta e sem foco, e a concentração se explica por uma sintonia fina com o problema. Trata-se aí de uma atitude de concentração pelo problema e no problema. A tendência é a eliminação da intermediação do saber anterior e das inclinações pessoais. O objetivo é atingir uma atenção movente, imediata e rente ao objeto-processo, cujas características se aproximam da percepção háptica.

A percepção háptica foi estudada no domínio do tato por G. Revesz (1950). O tato é uma modalidade sensorial cujos receptores estão espalhados por todo o corpo e que possui a qualidade de ser uma próximo-recepção, sendo seu campo perceptivo equivalente à zona de contato. Diferente da percepção tátil passiva, onde a estimulação é limitada ao tamanho do estímulo, a percepção háptica é formada por movimentos de exploração do campo perceptivo tátil, que visam construir um conhecimento dos objetos. A percepção háptica é então um bloco tátil-sinestésico que envolve uma construção a partir de fragmentos seqüenciais. Ela mobiliza a atenção e requer uma ampla memória de trabalho para que, ao fim da exploração, haja uma síntese, cujo resultado é um conhecimento do objeto (Hatwell, Streri \& Gentaz, 2000).

Estendendo o alcance do conceito a outros domínios sensoriais, Deleuze distingue a percepção háptica da percepção ótica. A percepção ótica se caracteriza pela organização do campo em figura e fundo. A segregação autóctone faz com que a forma salte do fundo e instala uma hierarquia, uma profundidade no campo. Além do dualismo figura-fundo, faz parte da percepção ótica a organização cognitiva no dualismo sujeito-objeto, que configura uma visão distanciada, característica da representação. O ótico não remete apenas ao domínio visual, mas este, em função de suas características, é aí dominante. Já a percepção háptica é uma visão próxima, onde não vigora a organização figura-fundo. Os componentes se conectam lado a lado, se localizando num mesmo plano igualmente próximo. O olho tateia, explora, rastreia, o mesmo podendo ocorrer com o ouvido ou outro órgão. De todo modo, a distinção mais importante aqui é entre percepção háptica e percepção ótica, e não entre os diferentes sentidos, com a visão, a audição e o tato. Para Deleuze, o movimento da percepção háptica se aproxima mais da exploração de uma ameba do que do deslocamento de um corpo no espaço. O movimento da ameba é regido por sensações diretas, por ações de forças invisíveis como pressão, estiramento, 
dilatação e contração. Não é o movimento que explica a sensação, mas, ao contrário, é a elasticidade da sensação que explica o movimento (Deleuze, 1981). Como uma antena parabólica, a atenção do cartógrafo realiza uma exploração assistemática do terreno, com movimentos mais ou menos aleatórios de passe e repasse, sem grande preocupação com possíveis redundâncias. Tudo caminha até que a atenção, numa atitude de ativa receptividade, é tocada por algo.

O toque é sentido como uma rápida sensação, um pequeno vislumbre, que aciona em primeira mão o processo de seleção. A idéia de uma seleção independente do interesse foi tematizada por E. Husserl (1998) no conceito de notar, que diz respeito ao contato leve com traços momentâneos ou com partes mais elementares que um objeto e que possuem força de afetação. O que é notado pode tornar-se fonte de dispersão, mas também de alerta ${ }^{2}$. Algo se destaca e ganha relevo no conjunto, em princípio homogêneo, de elementos observados. O relevo não resulta da inclinação ou deliberação do cartógrafo, não sendo, portanto, de natureza subjetiva. Também não é um mero estímulo distrator que convoca o foco e se traduz num reconhecimento automático. Algo acontece e exige atenção. $\mathrm{O}$ ambiente perceptivo traz uma mudança, evidenciando uma incongruência com a situação que é percebida até então como estável. É signo de que há um processo em curso, que requer uma atenção renovadamente concentrada. O que se destaca não é propriamente uma figura, mas uma rugosidade, um elemento heterogêneo. Trata-se aqui de uma rugosidade de origem exógena, pois o elemento perturbador provém do ambiente. Segundo a distinção estabelecida por Suely Rolnik $(1999,2006)$ a subjetividade do cartógrafo é afetada pelo mundo em sua dimensão de matéria-força e não na dimensão de matériaforma. A atenção é tocada neste nível, havendo um acionamento no nível das sensações, e não no nível das percepções ou representações de objetos.

Numa linguagem anglo-saxônica, a psicologia cognitiva denomina mismatch o fenômeno de irrupção de algo no campo perceptivo que instala uma situação de decalagem em relação ao estado cognitivo anterior. A decalagem significa um desnível na percepção presente. É o mismatch que está na origem da captura reflexa, imediata e irrefletida, da atenção (Mialet, 1999). A atenção do cartógrafo é capturada de modo involuntário, quase reflexo, mas não se sabe ainda do que se trata. Tem lugar uma reação de orientação. Como observado nos animais, os receptores sensoriais se voltam para a fonte da mudança. É preciso ver o que está acontecendo.

$\mathrm{O}$ toque pode levar tempo para acontecer e pode ter diferentes graus de intensidade. Sua importância no desenvolvimento de uma pesquisa de campo revela que esta possui múltiplas entradas e não segue um caminho unidirecional para chegar a um fim determinado. Através da atenção ao toque, a cartografia procura assegurar o rigor do método sem abrir mão da imprevisibilidade do processo de produção do conhecimento, que constitui uma exigência positiva do processo de investigação $a d$ hoc.

O gesto de pouso indica que a percepção, seja ela visual, auditiva ou outra, realiza uma parada e o campo se fecha, numa espécie de zoom. Um novo território se forma, o campo de observação se reconfigura. A atenção muda de escala. Segundo Vermersch (2002a), mudamos de janela atencional. No âmbito dos estudos da atenção, a noção de janela atencional serve para marcar que existe sempre um certo quadro de apreensão. Há um gesto que delimita um centro mais pregnante, em torno do qual se organiza momentaneamente um campo, um horizonte, enfim, uma periferia. A janela constitui uma referência espacial, mas não se limita a isto. Significa, antes de tudo, uma referência ao problema dos limites e das fronteiras da mobilidade da atenção. A tônica do conceito é a dinâmica da atenção, posto que há mobilidade no seio de cada janela e também passagem de uma janela para outras, que coexistem com a primeira, embora com um modo diferente de presença. Vermersch enumera cinco janelastipo, pautadas em suportes historicamente relacionados a práticas cognitivas, técnicas e culturais. São elas a jóia, a página do livro, a sala, o pátio e a paisagem. A primeira é uma janela micro, que funciona na escala da atividade do joalheiro, da bordadeira e do leitor minucioso. É uma atenção que se caracteriza por uma atividade eminentemente focal. Sem se distribuir e percorrer outros espaços além daquele visado, ela aumenta a magnitude do enquadramento e inibe as bordas do campo perceptivo. Sua tradução comportamental é a cessação dos movimentos. Um de seus traços característicos é que ela é capaz de produzir o fenômeno de cegueira atencional (Mack \& Rock, 1998), que consiste na eliminação absoluta do entorno, ou seja, do que está fora do foco. A segunda é a janela-página, através da qual se faz uma entrada no campo perceptivo, seguida de movimentos de orientação, comportando já indícios de distribuição da atenção. A terceira é a janelasala, que já permite a atenção dividida. Comporta focalização, mas também assimila uma multiplicidade de partes com graus de nitidez diferenciados. Aparece como ponto novo o movimento da cabeça e do próprio corpo no espaço. A janela-pátio é típica das atividades de deslocamento e orientação. Envolve detecção e é preponderante na atividade do caçador. A janela-paisagem é uma janela panorâmica, capaz de detectar elementos próximos e distantes, e conectá-los através de movimentos rápidos.

Cada janela cria um mundo e cada uma exclui momentaneamente as outras, embora outros mundos continuem co-presentes. Cada visada através de uma janela dá lugar, em sua escala, aos diversos gestos atencionais, possibilitando também mudanças de nível. Cabe sublinhar ainda que o movimento que chamamos de zoom não deve ser 
confundido com um gesto de focalização. Apenas a janelamicro é uma janela eminentemente focal. Quando a atenção pousa em algo nesta escala, há um trabalho fino e preciso, no sentido de um acréscimo na magnitude a na intensidade, o que concorre para a redução do grau de ambigüidade da percepção. De todo modo, é preciso ressaltar que em cada momento na dinâmica atencional é todo o território de observação que se reconfigura.

O reconhecimento atento é o quarto gesto ou variedade atencional. O que fazemos quando somos atraídos por algo que obriga o pouso da atenção e exige a reconfiguração do território da observação? Se perguntamos "o que é isto?" saímos da suspensão e retornamos ao regime da recognição. A atitude investigativa do cartógrafo seria mais adequadamente formulada como um "vamos ver o que está acontecendo", pois o que está em jogo é acompanhar um processo, e não representar um objeto. É preciso então calibrar novamente o funcionamento da atenção, repetindo mais uma vez o gesto de suspensão.

O que visamos com esta parada e como fica o funcionamento da atenção neste momento? H. Bergson (1897/ 1990a) colocou esta questão, quando de sua discussão sobre o estudo da atenção promovido por T. Ribot (1889). A atenção havia então sido definida como um movimento de detenção, mas Bergson argumenta que isto não soluciona o problema de seu funcionamento, mas apenas o coloca, pois cabe então explicar o trabalho do espírito correspondente, ou seja, como a atenção funciona quando ela se detém (Bergson, 1897/1990a, p.80). Nesta direção, propõe a distinção entre o reconhecimento automático e o reconhecimento atento. $\mathrm{O}$ reconhecimento automático tem como base e como alvo a ação. Reconhecer um objeto é saber servir-se dele. Os movimentos prolongam a percepção para obter efeitos úteis e nos afastam da própria percepção do objeto. Um exemplo é transitar por uma cidade que conhecemos, onde nos deslocamos com eficiência sem prestar atenção ao caminho percorrido. Ora, no caso do cartógrafo, é nítido que não pode se tratar de reconhecimento automático, pois o objetivo é justamente cartografar um território que, em princípio, não se habitava. Não se trata de se deslocar numa cidade conhecida, mas de produzir conhecimento ao longo de um percurso de pesquisa, o que envolve a atenção e, com ela, a própria criação do território de observação.

Bergson afirma que o reconhecimento atento tem como característica nos reconduzir ao objeto para destacar seus contornos singulares. A percepção é lançada para imagens do passado conservadas na memória, ao contrário do que ocorre no reconhecimento automático, onde ela é lançada para a ação futura. Bergson comenta sobre o reconhecimento atento:

enquanto no reconhecimento automático nossos movimentos prolongam nossa percepção para obter efei- tos úteis e nos afastam assim do objeto percebido, aqui, ao contrário, eles nos reconduzem ao objeto para sublinhar seus contornos. Daí o papel preponderante, e não mais acessório, que as lembrançasimagens adquirem (Bergson, 1897/1990a, p. 78).

Bergson (1897/1990a) afirma que sempre que o equilíbrio sensório-motor é perturbado, há uma exaltação da memória involuntária. Constantemente inibida pela consciência prática e útil do momento presente, isto é, pelo equilíbrio sensório-motor, essa memória aguarda simplesmente que uma fissura se manifeste entre a impressão atual e o movimento concomitante para fazer passar suas imagens. $\mathrm{O}$ interessante é que o conceito de reconhecimento atento desmonta a noção tradicional de reconhecimento, pautada na idéia do rebatimento da percepção numa imagem prévia ou esquema correspondente. A originalidade da análise bergsoniana é apontar que o processo de reconhecimento não se dá de forma linear, como um trajeto único ou uma marcha em linha reta. Não se faz através do encadeamento de percepções ou de associação cumulativa de idéias. $\mathrm{O}$ reconhecimento atento ocorre na forma de circuitos.

De modo geral o fenômeno do reconhecimento é entendido como uma espécie de ponto de interseção entre a percepção e a memória. O presente vira passado, o conhecimento, reconhecimento. No caso do reconhecimento atento, a conexão sensório-motora é inibida. Memória e percepção passam então a trabalhar em conjunto, numa referência de mão dupla, sem a interferência dos compromissos da ação. Para Bergson a memória não conserva a percepção, mas a duplica. A cada experiência com um objeto se formam dois registros: a imagem perceptiva e a imagem mnésica virtual. Quando do reconhecimento atento, a memória dirige à percepção imagens que se assemelham a ela. Se estas não a recobrem totalmente, novo apelo é lançado a regiões mais afastadas da memória e a operação pode prosseguir indefinidamente.

O gráfico do reconhecimento atento (Bergson, 1897/ 1990a) se articula em torno do objeto percebido e sua imagem-lembrança, virtual e correspondente. ${ }^{3}$ A partir desses dois pontos são desenhados circuitos sucessivos, cada vez mais amplos, forjando uma idéia de irradiação progressiva da atenção. O circuito mais amplo corresponde ao sonho. Segundo Bergson nos circuitos acionados no reconhecimento atento

todos os elementos, inclusive o próprio objeto percebido, mantêm-se em estado de tensão mútua como num circuito elétrico, de sorte que nenhum estímulo partido do objeto é capaz de deter sua marcha nas profundezas do espírito: deve sempre retornar ao próprio objeto (Bergson, 1897/1990a, p. 83).

A percepção não segue um caminho associativo operando por adições sucessivas e lineares. Através da aten- 
ção, ela aciona circuitos, se afastando do presente em busca de imagens e sendo novamente relançada à imagem atual, que progressivamente se transforma. O tecido da memória comporta um folheado, assim como o do objeto, que se refaz a cada instante. Há múltiplos níveis ou planos que tem como efeito desmontar o esquema do reconhecimento baseado no princípio de correspondência. Atiçado pela perturbação que opera uma fissura no domínio sensório-motor, o reconhecimento atento realiza um trabalho de construção. Percorrendo múltiplos circuitos em sucessivos relances, sempre incompletos, realiza diferentes construções, cujo resultado é um reconhecimento sem modelo mnésico pré-existente. Enfim o importante do reconhecimento atento, tal como descrito por Bergson, é a revelação da construção da percepção através do acionamento dos circuitos e da expansão da cognição. A percepção se amplia, viaja percorrendo circuitos, flutua num campo gravitacional, desliza com firmeza, sobrevoa e muda de plano, produzindo dados que, enfim, já estavam lá. A atenção atinge algo "virtualmente dado" (Bergson, 1897/1990a, p. 84), construindo o próprio objeto através dos circuitos que a atenção percorre.

\section{A Atenção Cartográfica e a Política Cognitiva Construtivista}

A ativação de uma atenção à espreita - flutuante, concentrada e aberta - é um aspecto que se destaca na formação do cartógrafo. Ativar este tipo de atenção significa desativar ou inibir a atenção seletiva, que habitualmente domina nosso funcionamento cognitivo. A noção de aprendizagem por cultivo, proposta Depraz, Varela e Vermersch (2003), indica uma noção de aprendizagem que não implica a criação de uma nova habilidade ou competência. Trata-se, aí também, de ativar uma virtualidade, de potencializar algo que "já estava lá". A atenção é entendida como um músculo que se exercita e sua abertura precisa sempre ser reativada, sem jamais estar garantida. O cultivo da atenção pelo aprendiz de cartógrafo é a busca reiterada de um tônus atencional, que evita dois extremos: o relaxamento passivo e a rigidez controlada. É nesta mesma direção que Deleuze e Guattari (1995) sublinham que a cartografia não é uma competência, mas uma performance. Ela precisa ser desenvolvida como uma política cognitiva do cartógrafo.

Procuramos demonstrar que a produção dos dados ocorre desde a etapa inicial da pesquisa de campo, que perde assim o caráter de uma simples coleta de dados. É preciso sublinhar que este processo continua com as etapas posteriores, atravessando as análises subseqüentes dos dados e a escrita dos textos, continuando ainda com a publicação dos resultados. Para sermos bastante precisos seria preciso incluir também a circulação do material escrito e a própria leitura do mesmo pelos interessados, tudo isto sem falar na contribuição dos participantes da pesquisa na produção coletiva do conhecimento. Quisemos, entretanto, apenas discutir, nos limites deste trabalho, que a construção ocorre desde o momento em que o cartógrafo chega ao campo. Naquele momento ele não apenas está desprovido de regras metodológicas para serem aplicadas, mas faz ativamente um trabalho preparatório. Informações, saberes e expectativas precisam ser deixados na porta de entrada e o cartógrafo deve pautar-se sobretudo numa atenção sensível, para que possa enfim, encontrar o que não conhecia, embora já estivesse ali, como virtualidade.

Através da descrição da dinâmica atencional, procuramos apontar que a cartografia constitui um método que assume uma perspectiva construtivista do conhecimento, evitando tanto o objetivismo quanto o subjetivismo. Objetivismo e o subjetivismo são duas faces de uma mesma política de pesquisa, o realismo cognitivo. Além de uma posição epistemológica, o realismo é uma política cognitiva corporificada em muitos pesquisadores, que por este motivo parece uma "atitude natural". A atitude de selecionar informações por critérios supostamente objetivos ou subjetivos situa-se neste contexto. Por sua vez, adotando uma política construtivista, a atenção do cartógrafo acessa elementos processuais provenientes do território - matérias fluidas, forças tendenciais, linhas em movimento bem como fragmentos dispersos nos circuitos folheados da memória. Tudo isto entra na composição de cartografias, onde o conhecimento que se produz não resulta da representação de uma realidade pré-existente. Mas também não se trata de uma posição relativista, pautada em interpretações subjetivas, realizadas do ponto de vista do pesquisador. Como defende Bruno Latour (2003) trata-se de um construtivismo que toma a sério os limites do saber e os constrangimentos da matéria. O cartógrafo é, neste sentido, guiado pelas direções indicadas por qualidades inesperadas e pela virtualidade dos materiais. A construção do conhecimento se distingue de um progressivo domínio do campo de investigação e dos materiais que nele circulam. Trata-se, em certa medida, de obedecer às exigências da matéria e de se deixar atentamente guiar, acatando o ritmo e acompanhando a dinâmica do processo em questão. Nesta política cognitiva a matéria não é uma força cega nem mero suporte passivo de um movimento de produção por parte do pesquisador. Ela não se submete ao domínio, mas expõe veios que devem ser seguidos e oferece resistência à ação humana. Mais que domínio, o conhecimento surge como composição.

Enfim, o método cartográfico faz do conhecimento um trabalho de invenção, tal como indica a etimologia latina do termo invenire - compor com restos arqueológicos. A invenção se dá através do cartógrafo, mas não por ele, pois não há agente da invenção. Ocorre que, ao final, realizando o que Bergson (1934/1979) denominou de mo- 
vimento retrógrado do pensamento, costumamos esquecer o lento e laborioso processo de construção do conhecimento, chegando a acreditar que ele não existiu e, se existiu, foi sem importância para os resultados a que se chegou. Trata-se de uma ilusão da inteligência, que devemos procurar apagar, bem como a ilusão de uma suposta atitude natural. Em seu lugar, pode ser cultivada a atenção cartográfica que, através da criação de um território de observação, faz emergir um mundo que já existia como virtualidade e que, enfim, ganha existência ao se atualizar.

\section{Notas}

1 O conceito de virtual é empregado aqui no sentido que lhe confere H. Bergson (1897/1990a, 1919/1990b). O virtual se atualiza segundo um processo de criação e de diferenciação. Neste sentido, distingue-se do possível, que se realiza através de um processo de limitação e de semelhança. Para a distinção detalhada entre virtual-atual e possível-real cf. Deleuze (1966). Um bom exemplo da atualização de uma virtualidade - como produção de algo que já estava lá - é a produção das mãos de um pianista através de repetidos treinos.

2 Para a classificação dos gestos em Husserl, cf Vermersch, (2002a, 2002b) e E. Husserl (1998).

3 Num texto posterior "Le souvenir du présent et la fausse reconnaissance" a referência ao objeto desaparece. A experiência dá lugar a uma bifurcação entre presente e passado, percepção e memória, que passam a coexistir. Cf. H. Bergson (1919/1990b).

\section{Referências}

Bergson, H. (1979). O pensamento e o movente - Introdução. In Bergson: Os Pensadores (pp. 99-151). São Paulo, SP: Abril Cultural. (Original publicado em 1934)

Bergson, H. (1990a). Matéria e memória. São Paulo, SP: Martins Fontes. (Original publicado em 1897)

Bergson, H. (1990b). L'énergie spirituelle. Paris, PUF. (Original publicado em 1919)

Caliman, L. V. (2006). A biologia moral da atenção. A constituição do sujeito (des)atento. Tese de Doutorado não-publicada, Universidade Estadual do Rio de Janeiro, Instituto de Medicina Social, RJ.

Deleuze, G. (1966). Le bergsonisme. Paris: PUF.

Deleuze, G. (1981). Francis Bacon: Logique de la sensation (2 vols.). Paris: Éd. de la Différence.

Deleuze, G. (2006). O abecedário de Gilles Deleuze. Retirado em mar. 2006, de http://www.ufrgs.br/faced/tomaz/abc1.htm

Deleuze, G., \& Guattari, F. (1995). Mil Platôs: Vol. 1. Rio de Janeiro, RJ: Ed. 34 Letras.

Depraz, N., Varela, F., \& Vermersch, P. (Eds.). (2003). On becoming aware. A pragmatic of experiencing. Amsterdam: John Benjamin.

Freud, S. (1969). Recomendações aos médicos que exercem a Psicanálise. In Obras Completas de Sigmund Freud: Vol. 12. Rio de Janeiro, RJ: Imago. (Original publicado em 1912)

Hatwell, I., Streri, A., \& Gentaz, E. (Eds.). (2000). Toucher pour connaître. Paris: PUF.

Husserl, E. (1998). De la sinthèse passive. Grenoble, França: Jérôme Milon.

James, W. (1945). Principios de Psicologia. Buenos Aires, Argentina: Corrientes. (Original publicado em 1890)
Kastrup, V. (2004). A aprendizagem da atenção na cognição inventiva. Psicologia \& Sociedade, 16(30), 07-16.

Kastrup, V. (2005). Políticas cognitivas na formação do professor e o problema do devir-mestre. Educação e Sociedade, 26(93), 12731288.

Laplanche, J., \& Pontalis, J.-B. (1976). Vocabulário de Psicanálise. Lisboa, Portugal: Moraes.

Latour, B. (2003). Promises of constructivism. Retirado em ago. 2006, de www.ensmp.fr/ latour/articles/article/087.html

Lima, R. (2004). Somos todos desatentos? Rio de Janeiro, RJ: Relume Dumará.

Mack, A., \& Rock, I. (1998). Inattentional blindness. Cambridge, MA: MIT Press/ Bradford Book.

Merleau-Ponty, M. (1999). Fenomenologia da percepção. São Paulo, SP: Martins Fontes. (Original publicado em 1945)

Mialet, J-P. (1999). L'attention. Paris: PUF.

Revesz, G. (1950). Psychology and art of the blind. London: Longmans Green.

Ribot, T. (1889). La psychologie de l'attention. Paris: Alcan.

Rolnik, S. (1999). Molda-se uma alma contemporânea. O vaziopleno de Lígia Clark. Retirado em ago. 2006, de http://www. pucsp.br/nucleodesubjetividade/suely\%20rolnik.htm

Rolnik, S. (2006). Cartografia sentimental. Porto Alegre, RS: Sulina/ Editora da Universidade Federal do Rio Grande do Sul.

Varela, F. (1995). Sobre a competência ética. Lisboa, Portugal: Edições 70.

Vermersch, P. (2002a). La prise en compte de la dynamique attentionelle: Eléments théoriques. Expliciter, 43, 27-39.

Vermersch, P. (2002b). L'attention entre phénoménologie et sciences expérimentales: Eléments de rapprochement. Expliciter, 44, 14-43.

Virgínia Kastrup é professora do Instituto de Psicologia e do Programa de Pós-Graduação em Psicologia da Universidade Federal do Rio de Janeiro. Endereço para correspondência: Instituto de Psicologia - Campus da Praia Vermelha - Av. Pasteur, 250 - Pavilhão Nilton Campos, Urca - Rio de Janeiro, RJ.

vkastrup@terra.com.br

O texto é resultado do projeto de pesquisa Atenção e invenção na produção coletiva de imagens, apoiado pelo CNPq. Agradeço aos companheiros do grupo de pesquisa Cognição e Subjetividade e em especial aos amigos André do Eirado e Eduardo Passos, pelas discussões e sugestões que acompanharam a elaboração deste texto.

\section{O Funcionamento da Atenção no Trabalho do Cartógrafo}

Virginia Kastrup

Recebido: 31/10/2006

$1^{\text {a }}$ revisão: 30/11/2006

Aceite final: 23/01/2007 